\title{
DO TAYLORISMO/FORDISMO À ACUMULAÇÃO FLEXÍVEL: IMPLICAÇÕES DOS REGIMES DE ACUMULAÇÃO PARA O MUNDO DO TRABALHO
}

\section{FROM TAYLORISM / FORDISM TO FLEXIBLE ACCUMULATION: IMPLICATIONS OF THE ACCUMULATION SCHEMES FOR THE WORLD OF WORK}

\author{
João Kaio Cavalcante de Morais ${ }^{1}$ \\ Dante Henrique Moura ${ }^{2}$
}

Resumo: Como atividade predominantemente humana, o trabalho se constitui enquanto ação de transformação da natureza para suprir as necessidades e os interesses dos homens. Apesar disso, nota-se que esse sentido foi desapropriado pela lógica do capital ao longo dos últimos três (3) séculos. Esse artigo tem como objetivo analisar a categoria trabalho no contexto dos regimes de acumulação de capital. Para isso, consultou-se os textos de Marx (1980), Harvey (2014), Antunes (2009), dentre outros. O que caracterizou essa pesquisa enquanto bibliográfica a partir de uma abordagem qualitativa. Percebeu-se, a partir dos textos dos autores, a existência de 2 (dois) regimes de acumulação: o Taylorismo/Fordismo e a Acumulação Flexível. O primeiro teve como principal característica a produção em massa e a divisão do trabalho em manual e intelectual. Já no segundo notou-se uma maior flexibilização da produção, com o intuito de atender as demandas do mercado, o que ocasionou mudanças significativas no mundo do trabalho, culminando em jornadas de trabalho mais flexíveis, empregos temporários e terceirizados, bem como perda de direitos trabalhistas.

Palavras-chaves: Trabalho - Capitalismo - Fordismo - Acumulação Flexível.

\begin{abstract}
Work is an action of transformation of nature to meet the needs and interests of men. This sense has been expropriated by the logic of capital over the last three (3) centuries. The purpose of this article is to analyze the category of labor in the context of capital accumulation regimes. We have recourse to Marx (1980), Harvey (2014), Antunes (2009). What characterized this research as a bibliographical from a qualitative approach. From the authors' texts, we can see the existence of two (2) regimes of accumulation: Taylorism / Fordism and Flexible Accumulation. The first one had as main characteristic the mass production and the division of the work in manual and intellectual. In the second, production was more flexible, in order to meet the demands of the market, which led to significant changes in the world of work, culminating in more flexible working hours, temporary and outsourced jobs, as well as loss of rights Labor markets.
\end{abstract}

Keywords: work - capitalismo - Fordism - Flexible build-up.

\footnotetext{
${ }^{1}$ João Kaio Cavalcante de Morais, Mestrando em Educação pelo IFRN, Professor de Biologia do Estado do Rio Grande do Norte - kaioifrn@gmail.com

2 professor do Instituto Federal do Rio Grande do Norte (IFRN) e coordenador do Programa de Pós-Graduação em Educação Profissional do IFRN - mestrado acadêmico (PPGEP) - dantemoura2014@gmail.com
} 


\section{INTRODUÇÃO}

Vinculado ao Programa de Pós-Graduação em Educação Profissional (PPGEP) e o Núcleo de Pesquisa em Educação (NUPED) do Instituto Federal de Educação Ciência e Tecnologia do Rio Grande do Norte (IFRN), o presente artigo surge como um instrumento avaliativo referente a disciplina de "Sociedade, Trabalho e Educação" cursada ao longo do primeiro $\left(1^{\circ}\right)$ período do mestrado acadêmico em questão.

No momento foi pedido que os mestrandos buscassem relacionar seus respectivos objetos de estudo da dissertação com as questões discutidas ao longo da disciplina. Para que se possa compreender tal intento é necessário localizar o leitor com relação a delimitação do objeto de estudo de caráter dissertativo, para que assim, possa ser compreendido o objeto de investigação do presente artigo.

A pesquisa dissertativa na qual centra-se o olhar no PPGEP tem como intuito constituir uma base de saberes docentes que ancore o trabalho do professor de Biologia no Ensino Médio Integrado (EMI). Parte-se da prerrogativa que o professor constrói e reconstrói seus saberes no trabalho e pelo trabalho (TARDIF, 2014). Logo, quando esse espaço de atuação apresenta características muito específica, faz-se necessário desvelar suas bases e/ou princípios.

As reflexões em torno do espaço de trabalho docente associada a uma profunda análise sobre a formação docente podem contribuir no sentido de propor uma base de saberes específicos ao trabalho do professor ${ }^{3}$. Ao enveredar por esse caminho, percebe-se que as discussões pontuais inerentes ao EMI, como por exemplo, a formação humana integral, o trabalho como princípio educativo e o currículo integrado, são relevantes uma vez que exigem do professorado uma postura ética, política e pedagógica específica dos demais espaços de atuação.

Para compreender essas especificidades é necessário desenvolver uma reflexão em torno da sociedade atual em que se encontra a humanidade, localizando o trabalho em meio a isso, haja vista que esse é um dos princípios norteadores da proposta do EMI. Logo, compreender o sentido do trabalho imerso na lógica do capital, pode contribuir para um melhor entendimento do espaço de atuação docente, nesse caso, o EMI.

Portanto, o presente artigo tem como objetivo analisar aspectos da categoria trabalho no contexto dos regimes de acumulação de capital. Para isso, foi consultada as obras

\footnotetext{
${ }^{3}$ Além disso, a pesquisa busca analisar a formação inicial e continuada do professor de Biologia para atuar no EMI, constituindo os dois (2) elementos base para construção/mobilização/articulação dos saberes docentes: espaço de trabalho e formação docente.
} 
de Marx (1980), Harvey (2014), Antunes (2009), dentre outros. O que caracterizou essa pesquisa enquanto bibliográfica a partir de uma abordagem qualitativa.

O estudo encontra-se organizado a partir da introdução e 3 (três) tópicos. No $2^{\circ}$ tópico discorre-se a respeito da categoria trabalho em seu sentido ontológico, bem como a desapropriação desse sentido pelo modo de produção capitalista. No $3^{\circ}$ tópico discute-se a questão dos regimes de acumulação capitalistas e as implicações destes para o mundo do trabalho. No $4^{\circ}$ e último tópico apresenta-se as conclusões.

\section{O MODO DE PRODUÇÃO CAPITALISTA E A ESPROPRIAÇÃO DO SENTIDO DO TRABALHO: UMA BREVE ABORDAGEM}

O trabalho, segundo a visão Marxiana - e marxista -, é uma realização essencialmente humana, foi no trabalho que os indivíduos, homens e mulheres, distinguiramse das formas de vida dos animais. O trabalho, nesse sentido, converte-se em um momento de mediação sociometabólica entre a humanidade e a natureza, ponto de partida para a constituição do ser social. Sem ele, a vida cotidiana não seria possível de se reproduzir (ANTUNES, 2009a).

De acordo com Antunes (2009a) se a vida humana se resumisse exclusivamente ao trabalho, seria a efetivação de um esforço penoso, aprisionado o ser social em uma única de suas múltiplas dimensões. Se a vida humana necessita do trabalho humano e de seu potencial emancipador, ela deve recusar o trabalho que aliena e infelicita. Isso evidencia que o ser humano se constitui além do trabalho, sendo este, uma das dimensões.

Marx (1980, p.59) comenta que como criador de valores de uso ${ }^{4}$ como trabalho útil, é "o trabalho, por isso, uma condição de existência do homem, independentemente de todas as formas de sociedade, eterna necessidade natural de mediação do metabolismo entre homem e natureza e, portanto, vida humana". Ainda remetendo aos estudos de Marx (1980,

\footnotetext{
${ }^{4}$ Os seres humanos se apropriam da natureza para satisfazer suas necessidade e vontades. Essa apropriação é um processo material incorporado nos atos de produção e consumo. Sob condição de produção de mercadoria, os atos de produção e consumos são separados pela troca. Mas a apropriação da natureza sempre vai permanecer. Esse lado material das mercadorias é capturado em suas relações os desejos e necessidade humana pelo conceito de seu valor de uso (HARVEY, 2013). Quando essa condição é apropriada pelo capitalista, ela deixa de apresentar uma perspectiva qualitativa (trabalho sobre condição de transformação da natureza) e passa a produzir valor para o dono do capital, numa relação quantitativa. Isso, em uma sociedade capitalista apresenta grande importância. Os produtores (donos do capital) usam uma determinada quantidade de dados -força de trabalho, matérias-primas e instrumentos de produção- para criar uma quantidade de produtos físicos que é usada para satisfazer os desejos e as necessidades de um determinado número de pessoas, a isso se dar o nome de valor de troca. De acordo com Marx (1980, p.116), o valor de troca é o "modo necessário de expressão ou forma de manifestação do valor".
}

Revista Labor Fortaleza/CE, jan/jul 2017 Vol. 01, nº 17, p. 62-72 ISSN 1983-5000 
p.120), o autor esclarece que "o trabalho útil é uma eterna necessidade natural de mediação do metabolismo entre homem e natureza e, portanto, da vida humana".

Ao mesmo tempo que os indivíduos transformam a natureza externa, alteram também a sua própria natureza humana, num processo de humanização, recíproca que converte o trabalho social num elemento central do desenvolvimento da sociedade (ANTUNES, 2009a).

Ao longo da história, o trabalho vem assumindo várias formas, como o trabalho escravo, o trabalho autônomo dos artesãos pré-revolução industrial. A partir da revolução industrial, sob a hegemonia ${ }^{5}$ do modo de produção capitalista, o trabalho assume majoritariamente a forma de emprego, na qual o trabalhador vende a sua força de trabalho ${ }^{6}$ para o detentor do capital $^{7}$ no mercado de trabalho (MOURA, 2013).

Sendo assim, percebe-se que o trabalho foi se constituindo, ao longo da história, a partir de uma perspectiva distante do sentido exposto nos parágrafos anteriores. Nota-se que a partir da sociedade capitalista, a conjuntura e a apropriação do trabalho pelos donos do meio de produção foi delimitando um percurso que se encontra ainda muito presente em nossa atual sociedade: o trabalho na forma de emprego.

Nesse sentido, o que era uma finalidade central do ser humano, converte-se em meio de subsistência e de interesses. A força de trabalho torna-se uma mercadoria ${ }^{8}$, cuja finalidade é criar novas mercadorias e valorizar o capital. Converte-se em meio e não em primeira necessidade de realização humana (HARVEY, 2013; ANTUNES, 2009a).

O modo de produção capitalista, portanto, se apropriou da condição natural do homem para seu próprio interesse. Isso foi possível a partir de um conjunto de princípios e fundamentos ${ }^{9}$ muito bem elaborados no qual tornou o trabalho uma mercadoria.

O trabalho, dentro desse modo de produção capitalista, encontra-se imbricado na produção gerando lucros para o dono do capital, que se utiliza da força de trabalho do trabalhador para obter mais capital -leia-se mais lucros. Harvey (2013, p.52) explica essa

\footnotetext{
${ }^{5}$ De acordo com Spinelli e Lyra (2007) pode-se compreender hegemonia como a capacidade que uma classe tem de -aliada a outras classes ou frações destas- conquistar, manter e ampliar sua esfera de liderança sobre a sociedade como um todo.

${ }^{6}$ Entende-se, a partir dos estudos de Harvey (2013, p.70), a força de trabalho como "a capacidade de realizar na forma-mercadoria certa quantidade de tempo de trabalho socialmente necessário".

${ }^{7}$ Um capitalista, de acordo com Harvey (2013) é um agente econômico que coloca dinheiro e mercadorias em circulação para produzir mais dinheiro.

${ }^{8}$ Mercadoria é uma "incorporação dos valores de uso e de troca" (MARX, 1980, p.178). Harvey (2013, p.59) comenta que "o único atributo que todas as mercadorias têm em comum é o fato de serem produtos do trabalho humano".

${ }^{9}$ Não é objetivo dessa investigação discorrer profundamente a respeito da organização do modo de produção capitalista. Sugere-se, para maiores aprofundamentos, a leitura de Marx (1980) e Harvey (2013).
} 
dinâmica ao pontuar que os trabalhadores dependem da mercadoria capitalista para "satisfazer suas necessidades, ao mesmo tempo que os produtores de mercadoria dependem dos trabalhadores para gastar o seu dinheiro com as mercadorias que os capitalistas podem produzir".

Isso quer dizer que os trabalhadores, submetidos a hegemonia do capital, estão subordinados duplamente a dinâmica do modo de produção capitalista, haja vista que ao mesmo tempo que eles vendem sua força de trabalho para o dono do capital, eles também compram - por decorrência do valor da sua força de trabalho fixada no contrato de empregoas mercadorias que estão à venda -por exemplo, carro, casas e eletrodomésticos.

Uma vez que os capitalistas adquirem força de trabalho, eles podem coloca-la para trabalhar de maneiras benéficas para eles próprios. Como os capitalistas compram certa extensão de tempo durante a qual mantêm os direitos de uso da força de trabalho, eles podem organizar o processo de produção - esse fator é fundamental no modo de produção capitalista e ao longo dos anos passou por algumas modificações- para garantir que os trabalhadores, durante aquele período, produzam um valor maior do que recebem (HARVEY, 2013).

A análise da produção e da troca de mercadorias revela a existência de dois papéis distintos e opostos na sociedade capitalista (HARVEY, 2013). Marx (1980, p.60) evidencia que essas duas (2) duas classes são as "personificações das relações econômicas, como suporte das quais elas se defrontam umas com as outras".

Ou seja, essas classes vivem, dentro do modo de produção capitalista, em constante conflito, apesar de uma não existir sem a outra. Marx (1980) ainda aborda as implicações sociais, morais, psicológicas e políticas desses papéis distintos e parte de uma representação de duas (2) classes da estrutura social capitalista, nessa produção optou-se por chama-las de classe dominante e classe trabalhadora.

Harvey $(2013$, p.71) destaca que a relação entre o capital e o trabalho, no cerne da produção capitalista, não tem uma base natural, ela surge como resultado de um processo histórico específico -a saber, o apogeu da classe dominante e a submissão da classe trabalhadora. $\mathrm{O}$ autor lembra que

nenhuma das classes, no modo de produção capitalista, pode viver uma sem a outra, embora a antítese entre elas seja profunda. Seu desenvolvimento mútuo assume várias formas intermediárias e segue de forma desigual por setor e por região. Mas, finalmente, a relação entre o capital e o trabalho se torna hegemônica e dominante dentro de uma formação social, no sentido de que toda a estrutura e direção do desenvolvimento dança principalmente conforme a música. E nesse ponto se justifica chamarmos essa sociedade uma sociedade capitalista. 
Nesse sentido, entende-se que a humanidade, de uma forma geral, vivencia uma sociedade capitalista, caracterizada por duas (2) classes sociais, em que uma não se sustenta sem a outra. Por isso, compreende-se que a história dessa sociedade é permeada por conflitos e contradições. Apesar dessas contradições, percebe-se que uma classe especificamente, se sobressai a outra, justamente por ser detentora dos meios de produção, trata-se da classe dominante.

\section{DO TAYLORISMO/FORDISMO À ACUMULAÇÃO FLEXÍVEL TRANSFORMAÇÕES NO SENTIDO DO TRABALHO}

Tendo a compreensão que o trabalho, em seu sentido histórico, encontra-se submetido à lógica do capital, pretende-se, nesse tópico, mesmo que brevemente, discorrer a respeito das implicações dos regimes de acumulação capitalista para o mundo do trabalho.

Para que se possa alcançar tal intento, é necessário a conceituação do termo regime de acumulação. Harvey (2014, p.117) o compreende como "a estabilização, por um longo período, da alocação do produto líquido entre consumo e acumulação; ele implica alguma correspondência entre a transformação tanto das condições de produção como das condições de reprodução dos assalariados".

Harvey (2014) esclarece que um regime de acumulação é organizado a partir de regras e processos sociais interiorizados que tem o nome de modo de regulamentação. No cerne desse modo de regulamentação encontra-se as classes que movimentam o regime de acumulação: a classe dominante e a classe trabalhadora.

De acordo com Mészáros (2010, p.79) “o capital, de uma forma geral, não pode ter outro objetivo que não sua própria autorreprodução, à qual tudo, da natureza a todas as necessidades e aspirações humanas, deve se subordinar de modo absoluto". Ou seja, os regimes de acumulação e respectivamente seu modo de regulamentação tem o intuito de controlar o capital e o trabalho, subordinando-os aos seus próprios interesses.

O modo de produção capitalista já vivenciou dois (2) regimes de acumulação: o Taylorismo/Fordismo e a Acumulação Flexível. Um fator primordial se faz presente entre um regime e outro: o esgotamento da acumulação. A esse esgotamento dá-se o nome de crise cíclica do capital. 
Com relação ao Taylorismo/Fordismo, Castells (1999, p.212) evidencia que o

modelo de produção em massa, ou simplesmente fordismo, fundamentou-se em ganhos em ganhos de produtividade obtidos por economias de escala em um processo mecanizado de produção padronizada com base em linhas de montagem, sob as condições de um grande mercado por uma forma organizacional específica: a grande empresa estruturalizada nos princípios de integração vertical e na divisão social e técnica institucionalizada de trabalho. Esses princípios estavam inseridos nos métodos de administração conhecidos como taylorismo e organização científica do trabalho.

Logo, o Fordismo, tem como base um pressuposto que antecede a sua própria gênese, o Taylorismo. Segundo Cattani (1997), o Taylorismo pode ser considerado o sistema de organização do trabalho, especialmente industrial, baseado na separação das funções de concepção e planejamento das funções de execução, na fragmentação e na especialização das tarefas, no controle de tempo e movimentos e na remuneração por desempenho. Esses princípios de racionalidade produtiva do trabalho foram sistematizados e desenvolvidos pelo engenheiro norte-americano Frederick Winslow Taylor (1856-1915).

Apesar das sucintas e inicias, as reflexões do Castells (1999) e do Cattani (1997) já norteia os pressupostos desse regime de acumulação, em que se fundamentou basicamente no aumento de produtividade -e lucro- através de um processo mecanizado de produção de massa em linhas de montagem. Para alcançar tal intento, utilizou-se de um já conhecido instrumento, o Taylorismo. Por isso, nessa produção, intitula-se como Taylorismo-Fordismo.

Os princípios da administração científica era um influente tratado que descrevia como a produtividade do trabalho podia ser radicalmente aumentada através da decomposição de cada tarefa e da organização das mesmas em fragmentos segundo padrões rigorosos de tempo e estudo de movimento (HARVEY, 2014). Percebe-se, portanto, implicações fundamentais no trabalho, a partir do momento em que se apropria a fragmentação e a otimização do mesmo com o objetivo de aumentar a produtividade.

Observou-se, portanto, uma acentuada racionalização de operações realizadas pelos trabalhadores, combatendo o desperdício na produção, reduzindo o tempo e aumentando o ritmo de trabalho, visando a intensificação das formas de exploração. O trabalho, nesse sentido, era parcelar e fragmentado, o que reduziu a ação operária a um conjunto repetitivo de atividade cuja somatória resultava no trabalho coletivo (ANTUNES, 2009b).

Antunes (2009b) comenta que foi a partir desse momento que o trabalho se dividiu em intelectual e manual. O primeiro grupo de sujeitos (muito reduzido), elaborava, 
enquanto que o segundo, executava. Os trabalhadores desenvolviam suas atividades de forma individualizadas, entretanto um elemento fazia a mediação e determinativa o tempo de trabalho, a esteira. A cargo do trabalho intelectual e do desenvolvimento das atividades que exerciam maior nível de reflexão, ficava a gerência científica.

Antunes (2009b) diz que a introdução da organização científica Taylorista do trabalho na indústria automobilística e sua fusão com o fordismo acabaram por representar a forma mais avançada da racionalização capitalista do processo de trabalho ao longo de várias décadas do século XX, sendo somente entre o final dos anos 1960 e início dos anos 1970 que esse padrão produtivo começou a dar sinais de esgotamento.

Consequentemente, o capital buscou alternativas para contornar sua própria crise. Antunes (2009b, p.33) abrange mais essa discussão ao afirmar que

\begin{abstract}
Como resposta à sua própria crise, iniciou-se um processo de reorganização do capital e de seu sistema ideológico e político de denominação, cujos contornos mais evidentes foram o advento do neoliberalismo, com a privatização do Estado, a desregulamentação dos direitos do trabalho e a desmontagem do setor produtivo estatal. A isso se seguiu também um intenso processo de reestruturação da produção e do trabalho, com vistas a dotar o capital do instrumental necessário para repor os patamares de expansão anteriores.
\end{abstract}

Antunes (2009b) explica que o capital deflagrou várias transformações no próprio processo produtivo, por meio da constituição das formas de acumulação flexível, das formas de gestão organizacional, do avanço tecnológico, dos modelos alternativos ao binômio taylorismo/fordismo, em que se destaca especialmente o toyotismo ou o modelo japonês.

A esse regime de acumulação, chama-se, nessa produção, de acumulação flexível, coadunando com a nomenclatura utilizada por Harvey (2014). O autor explicita que esta é marcada por um confronto direto com a rigidez do fordismo, haja vista que ela se apoia na flexibilidade dos processos de trabalho, dos mercados de trabalho, dos produtos e dos padrões de consumo.

É possível dizer que o padrão de acumulação flexível articula um conjunto de elementos de continuidade e descontinuidade que acabam por conformar algo relativamente distinto do padrão taylorista/fordista de acumulação. Ele se fundamenta num padrão produtivo organizacional e tecnologicamente avançado, resultado da introdução de técnicas de gestão da força de trabalho próprias da fase informacional, bem como da introdução ampliada dos computadores no processo produtivo e de serviços. Desenvolve-se em uma estrutura 
produtiva mais flexível, recorrendo frequentemente à desconcentração produtiva, às empresas terceirizadas (ANTUNES, 2009b).

Isso teve influência direta no mundo do trabalho, no qual, segundo Harvey (2014), passou por uma radical reestruturação. Diante do cenário de crise, o capital tirou proveito da situação e começou a impor regimes e contratos de trabalhos mais flexíveis. O autor ainda cita a dificuldade em desenvolver um quadro que reflita esse cenário de empregos mais flexíveis, justamente por ser muito volátil. Mas, o que fica de mais característico nesse momento histórico é a aparente redução do emprego regular em favor do crescente uso do trabalho em tempo parcial, temporário ou subcontratado.

Antunes (2009b) sinaliza um quadro similar ao levantado por Harvey (2014) ao comentar que as mudanças na forma de organização das empresas têm alteração direta no mundo do trabalho: desregulamentação enorme dos direitos do trabalho, que são eliminados cotidianamente em quase todas as partes do mundo onde há produção industrial e de serviços; aumento da fragmentação no interior da classe trabalhadora; precarização e terceirização da força humana que trabalha; destruição do sindicalismo de classe e sua conversão num sindicalismo dócil, de parceria.

Como resultado a isso, surgem os trabalhos em equipe e o envolvimento participativo dos trabalhadores, que na gênese requer uma participação manipulada e que preserva na essência, as condições do trabalho alienado e estranhado. $\mathrm{O}$ trabalho polivalente, multifuncional e qualificado, combinado com uma estrutura mais horizontalizada e integrada, tem como finalidade a redução do tempo de trabalho (ANTUNES, 2009b).

De acordo com Antunes (2009b), essas mudanças desregulamentam os direitos do trabalho, que são eliminados cotidianamente em quase todas as partes do mundo onde há produção industrial e de serviços; aumento da fragmentação no interior da classe trabalhadora; precarização e terceirização da força humana que trabalha; destruição do sindicalismo de classe e sua conversão num sindicalismo dócil, de parceria.

Trata-se, portanto, de um movimento de reorganização do trabalho no qual a principal finalidade é a intensificação das condições de exploração do trabalhador e, consequentemente, do trabalho, reduzindo ou até mesmo eliminando o trabalho improdutivo e a força sindical da classe trabalhadora.

Dessa forma, percebe-se que a mudança de um regime de acumulação para o outro, decorrente de uma crise e de pressões advindas de alguns setores da sociedade inclusive os trabalhistas-, fizeram com que o capital fosse condicionado a modificar a organização da produção nas fábricas, passando de um modelo rígido, de alta produção, para 
um modelo mais flexível, que atendesse as demandas do mercado. Isso teve forte influência na organização e gerenciamento do trabalho, ocasionando mais trabalhos temporários e terceirizados e consequentemente um enfraquecimento dos sindicados e perda de direitos trabalhistas.

\section{CONSIDERAÇÕES FINAIS}

Com intuito de discutir a respeito do sentido do trabalho no modo de produção capitalista e mais precisamente nos regimes de acumulação, o presente texto evidenciou que o trabalho, em seu sentido ontológico, apresenta-se como ação fundante no desenvolvimento humano e na relação com a natureza. Em contrapartida, viu-se que o modo hegemônico de produção atual desapropriou esse sentido inato transformando o trabalho em força de trabalho, a partir de um contrato, ou um emprego.

Nesse sentido, dentro da própria lógica do capital, o trabalho foi sendo desapropriado da condição histórica a partir dos regimes de acumulação do capital, que demandou mudanças significativas no sentido do trabalho. Dentre os regimes, pode-se citar o Taylorismo/Fordismo e a Acumulação Flexível. O primeiro teve como principal característica a divisão do trabalho em manual e intelectual. O segundo, por sua vez, chama atenção pelos mecanismos flexibilizados de trabalho, aumentando assim os empregos temporários e terceirizados, diminuindo os direitos trabalhistas.

Dessa forma, compreende-se que essa produção contribuiu para a investigação de caráter maior, como já explicitado No tópico situando o estudo, haja vista que pôde-se compreender o sentido do trabalho na sociedade capitalista e a sinalização da divisão do trabalho em intelectual e manual, bem como as implicações disso para o trabalho docente, haja vista que o professor tanto exerce uma função de formação dos sujeitos para o mundo do trabalho, bem como eles também são sujeitos imersos na lógica do capital. Seu trabalho pode contribuir com a lógica do capital, por outro lado podem posicionar os estudantes numa perspectiva contra hegemônica.

\section{REFERÊNCIAS}

ANTUNES, Ricardo. Século XXI: Nova era da precarização estrutural do trabalho. In: ANTUNES, Ricardo; BRAGA, Ruy (Org.). Infoproletários: degradação real e virtual do trabalho. 3 ed. São Paulo: Boitempo, 2009a. p. 231-239a. 
Os sentidos do trabalho: ensaio sobre a afirmação e a negação do trabalho. São Paulo: Boitempo, 2009b.

CASTELLS, Manuel. A sociedade em rede. 6. ed. São Paulo: Paz e Terra, 1999.

CATTANI, Antonio David. Taylorismo, in Cattani, Antonio David (org), Trabalho e Tecnologia: dicionário crítico. Petrópolis: Vozes, 1997.

HARVEY, David. A Condição Pós-moderna. 14 ed. São Paulo: Loyola. 2014.

Os limites do capital. 2013. ed. São Paulo: Boitempo, 2013.

MARX, KARL. O capital: crítica da economia política. 5. ed. Livro 1 v. 1. Rio de Janeiro: Civilização Brasileira, 1980.

MÉSZÁROS, István. Atualidade histórica da ofensiva socialista. São Paulo: Boitempo, 2010.

MOURA, Dante Henrique. Mudanças na sociedade brasileira dos anos 2000 limitadas pela hegemonia do neoliberalismo: implicações para o trabalho e para a educação. In: MOURA, Dante Henrique (Org.). Produção de Conhecimento, Políticas Públicas e Formação Docente em Educação Profissional. Campinas: Mercado de Letras, 2013. p. 109-141.

SPINELLI, José Antonio; LYRA, Rubens Pinto. Capitalismo de acumulação flexível e as categorias gramscianas. Cronos,Natal, v. 8, n. 2, p.567-587, jul. 2007.

TARDIF, Maurice. Saberes docentes e formação profissional. 12 ed. Petrópolis, RJ: Vozes, 2014. 